\title{
Evaluation of Mass Transfer Rate of Dissolved Gases in Transformer Oils
}

DOI:

10.1109/CMD.2016.7757865

\section{Document Version}

Accepted author manuscript

Link to publication record in Manchester Research Explorer

\section{Citation for published version (APA):}

Wang, X., Wang, Z., Liu, Q., Wilson, G., Jarman, P., \& Walker, D. (2016). Evaluation of Mass Transfer Rate of Dissolved Gases in Transformer Oils. In Condition Monitoring and Diagnosis (CMD), 2016 International

Conference on https://doi.org/10.1109/CMD.2016.7757865

\section{Published in:}

Condition Monitoring and Diagnosis (CMD), 2016 International Conference on

\section{Citing this paper}

Please note that where the full-text provided on Manchester Research Explorer is the Author Accepted Manuscript or Proof version this may differ from the final Published version. If citing, it is advised that you check and use the publisher's definitive version.

\section{General rights}

Copyright and moral rights for the publications made accessible in the Research Explorer are retained by the authors and/or other copyright owners and it is a condition of accessing publications that users recognise and abide by the legal requirements associated with these rights.

\section{Takedown policy}

If you believe that this document breaches copyright please refer to the University of Manchester's Takedown Procedures [http://man.ac.uk/04Y6Bo] or contact uml.scholarlycommunications@manchester.ac.uk providing relevant details, so we can investigate your claim.

\section{OPEN ACCESS}




\section{Evaluation of Mass Transfer Rate of Dissolved Gases in Transformer Oils}

\author{
X.F. Wang, Z.D. Wang, Q. Liu \\ The University of Manchester \\ Manchester \\ M13 9PL, UK
}

\author{
G. Wilson, P. Jarman \\ National Grid \\ Warwick \\ CV34 6DA, UK
}

\author{
D. Walker \\ Scottish Power \\ Blantyre \\ G72 0HT, UK
}

\begin{abstract}
Dissolved Gas Analysis (DGA) method is one of the most effective techniques to monitor the condition of transformers. In this method, free gas leakage condition is required as any leakage of dissolved gases might distort the DGA results and mislead the diagnosis of transformer fault. In this paper, a mass transfer model based on two-film theory is built to simulate the gas leakage process from transformer oil when it is in contact with air. The mass transfer coefficients of dissolved fault gases in mineral oil have been calculated at different temperatures based on an experiment. The mass transfer coefficient at certain temperature can be predicted by the Arrhenius equation. According to the ascertained mass transfer coefficient, oil surface and volume, gas leakage from a sampling rate can be estimated. For practical application, the gas leakage from oil sampled by bottle is quantified.
\end{abstract}

Index Terms - dissolved gas analysis, transformer, condition monitoring, mineral oil, oil sampling, mass transfer

\section{INTRODUCTION}

Dissolved Gas Analysis (DGA) is widely accepted as a transformer condition monitoring technique. It is regarded as one of the most effective method to diagnose oil-immersed transformer faults [1-3].

Insulating liquids in oil-filled equipment can be sampled for various types of oil tests. For DGA test, oil can be sampled with syringes, ampoules or bottles. The oil sample volume ranges from $25 \mathrm{~mL}$ to $100 \mathrm{~mL}$ [4].

In general, there are three major steps in sampling the oil. Firstly, the sampling vessel should be correctly connected to the proper sampling point. The sample should be taken from a point where the representative of the bulk oil in the equipment. Subsequently, the sampling vessel will be flushed by some oil in order to eliminate contaminations. The flushed oil will be disposed to a waste oil container. Finally, the oil sample will be taken and sealed by the sampling vessel.

Oil sampled with syringe is properly sealed during the whole sampling process. However, the oil will inevitably get in contact with air when sampling by bottles. Due to the volatility of dissolved gases, it is suggested that a new sample should be taken if the time to fill the bottle exceeds a few minutes [4]. In the other words, the oil sample for DGA is ineffective if the oil sampled by bottle is left open in air for a few minutes. Nevertheless, the gas leakage amount has not been identified in this process. Hence, it is essential to quantify the gas leakage amount in bottle sampling process during this time period.

In this paper, the dissolved gas leakage amount from oil to air was estimated. Firstly, the dissolved gas leakage process was simulated by a mass transfer model. Then, an experiment was performed to derive the necessary coefficients in the model. Based on this model, the dissolved gas leakage rate under known oil, vessel and temperature condition could be calculated.

\section{THEORETICAL MODEL}

\section{A. Mass Transfer Model}

The mass transfer model based on two-film theory [5] is accepted to simulate mass transfer between liquid and gas phase [6]. Under the circumstances where the dissolved gases transfer between limited volume of liquid and atmosphere, the concentrations of the gases in bulk gas phase can be regarded as constant, i.e. the initial bulk gas concentration is same as the final gas concentration. The mass transfer model for dissolved gas leakage process is demonstrated in Fig.1. The initial state and final state are shown as red and blue colours, respectively. Assuming initially the transferred substances such as dissolved gas molecules in liquid phase are denser than in gas phase, the substances will flow from bulk liquid into bulk gas. The two-film theory suggests two thin films very close to the interface. In these two films the concentrations of the substances are linearly changing. According to the Fick's law of diffusion, the mass fluxes in these two films are constant. They should be equal to each other, since there are no molecules accumulated on the interface. In the bulk liquid and gas volume, the substances are homogeneously distributed and the concentrations are constant.

Considering the whole process of mass transfer, the profile of the substances concentration in liquid can be described as shown in (1),

$$
\frac{d c}{d t}=\frac{K * A}{V} *\left(c_{l}-c\right)
$$

where, $c$ and $c_{l}$ are the instantaneous and final dissolved gas concentration in oil, in ppm, respectively; $K$ is the mass transfer 
coefficient, in $\mathrm{m} / \mathrm{h} ; A$ is the liquid interface area, in $\mathrm{m}^{2} ; V$ is the liquid volume, in $m^{3}$.

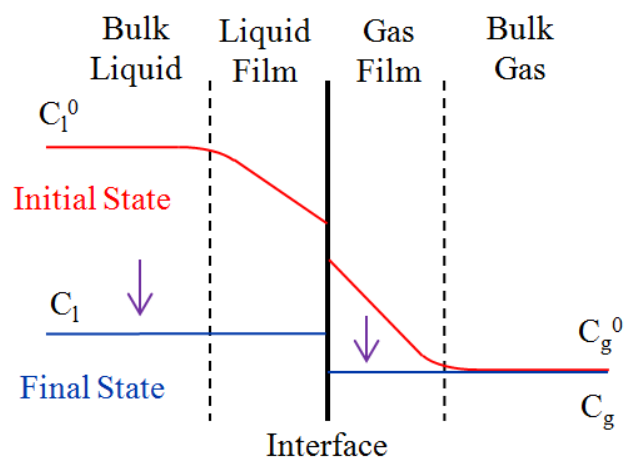

Fig.1. Two-film mass transfer model simulates the dissolved gas leakage.

The final concentration $c_{l}$ can be derived based on the mass transfer condition. For example, a common situation is dissolved gas leaks into atmosphere. In this case, the final concentration of atmospheric gases such oxygen, nitrogen or carbon oxides will be in equilibrium with their concentration in air. The final concentration of other gases which are not main components of air will be zero which means these gases will transfer into air and rapidly dissipated away. Considering the latter case, the solution of (1) is shown in (2),

$$
c=c_{0} * \exp \left(-\frac{K * A}{V} * t\right)
$$

where, $c$ is the instantaneous concentration at time $t$ in liquid, in $p p m ; c_{0}$ is the initial concentration, in $\mathrm{ppm}$.

Based on (2), concentration changing can be calculated in terms of ascertained mass transfer coefficient, liquid volume and interface area. On the other hand, the concentration changing profile of a known volume and interface area of liquid can derive the mass transfer coefficient. The model assumes environmental temperature is stable since the mass transfer coefficient is temperature dependent.

\section{B. Temperature Dependent}

The mass transfer coefficient $K$ in (1) and (2) is the key factor to determine the dissolved gas leakage property. According to the two-film theory model, the relationship between mass transfer coefficient and diffusion coefficient in the two phases is shown as (3),

$$
\frac{1}{K}=\frac{1}{k_{l}}+\frac{1}{H * k_{g}}
$$

where, $K$ is the mass transfer coefficient of the two phase system; $k_{l}$ and $k_{g}$ are the mass transfer coefficients in liquid and gas phase, respectively; $H$ is the Henry's law constant.

The mass transfer coefficient of gas in gas phase $k_{g}$ is vastly larger than that in liquid phase [7] and Henry's law constant $H$ is larger than unity. Hence, the second term in (3) is negligible.
The mass transfer coefficient $K$ can be regarded similar to the coefficient of gas in liquid phase $k_{l}$. This indicates that the mass transfer process of dissolved gas is controlled by the condition in the liquid phase.

As the mass transfer coefficient in liquid phase is predominated by the diffusion coefficient. The diffusion coefficient is temperature dependent and can be predicted by the Arrhenius equation [8]. Therefore, the relationship between mass transfer coefficient and temperature can be expressed as (4) below,

$$
K=A * \exp \left(-\frac{E_{A}}{R * T}\right)
$$

where, $K$ is the mass transfer coefficient; $A$ is the pre-exponential factor; $E_{A}$ is the activation energy; $R$ is the universal gas constant; $T$ is the temperature.

Equation (4) is dependent on two parameters. If the pre-exponential factor $A$ and activation energy $E_{A}$ are confirmed, the relationship between mass transfer coefficient $K$ and temperature $T$ can be determined.

\section{EXPERIMENTAL SETUP}

An experiment has been designed to estimate the mass transfer coefficients of DGA related fault gases in mineral oil and its relationship with temperature. The experimental setup is shown in Fig.2. In this work, Gemini $\mathrm{X}$ was tested as mineral oil for transformers.

Firstly, a localized thermal fault was generated in the tested oil to generate dissolved fault gases. The hotspot temperature of thermal fault was much higher than $700{ }^{\circ} \mathrm{C}$. Under such fault level, large amount of fault gases could be generated in oil. Table 1 lists the initial concentration of oil tested at $80^{\circ} \mathrm{C}$ as an example. By changing the thermal fault duration and heating element size, the initial gas concentration levels can be adjusted. It has been verified by repeated experiments that the tested mass transfer coefficient is independent from oil with different initial gas concentration levels.

Table 1. Initial gas levels of one oil tested at $80^{\circ} \mathrm{C}$.

\begin{tabular}{|c|c|c|c|c|c|}
\hline Gas & $\mathbf{H}_{\mathbf{2}}$ & $\mathbf{C H}_{\mathbf{4}}$ & $\mathbf{C}_{2} \mathbf{H}_{\mathbf{6}}$ & $\mathbf{C}_{2} \mathbf{H}_{\mathbf{4}}$ & $\mathbf{C}_{2} \mathbf{H}_{\mathbf{2}}$ \\
\hline $\begin{array}{c}\text { Initial Gas Level } \\
(\mathbf{p p m})\end{array}$ & 1501 & 1919 & 646 & 4733 & 200 \\
\hline
\end{tabular}

Subsequently, two litres of the oil with dissolved gases was heated in an air circulation oven to a pre-set temperature in a 3-litre glass beaker. The oil surface area was measured. Due to the continuous air exchange, the gas combination in the oven was similar to atmosphere. A preliminary test showed that the bulk oil temperature could be heated to the oven operation temperature within three hours.

Then, the Transfix on-line DGA monitor continuously measured the dissolved gases concentrations in the tested oil. During operation, $50 \mathrm{~mL}$ oil was pumped into the Transfix where the dissolved gas was extracted and detected. After detection, the sampled oil was returned back. A whole detection cycle of Transfix could be completed within one hour. 
The advantage of the Transfix on-line DGA monitor over other devices in this experiment was that the oil was not continuously circulated. The effect of DGA measurement on mass transfer process would be minimized. Detection period in this test was set as per three hours to mitigate the disturbance on oil temperature. Accuracies and detection ranges of the Transfix on-line DGA monitor are listed in Table 2.

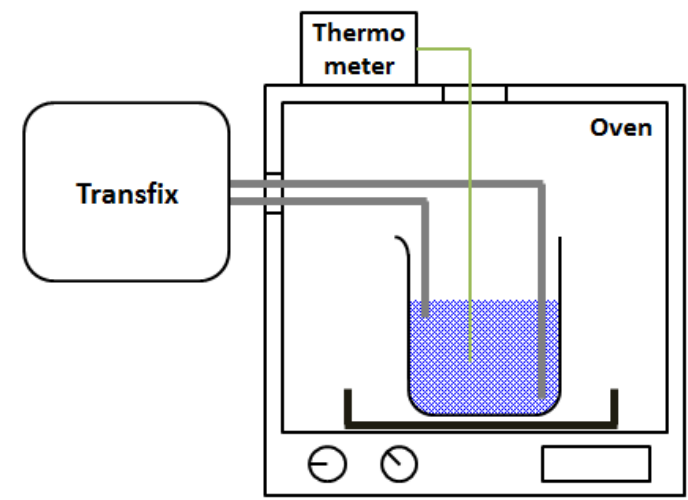

Fig.2. Mass transfer coefficient measurement test setup.

The dissolved gas contents were measured once the tested oil has been put into the oven. Measurements in the first 3 hours were neglected due to the unstable oil temperature. Once the concentration of any gas was lower than the detection limit of the online DGA monitor, the measurements were neglected as well.

Table 2. Accuracy and detection range of Transfix online DGA monitor.

\begin{tabular}{|c|c|c|c|c|c|}
\hline Gas & $\mathbf{H}_{\mathbf{2}}$ & $\mathbf{C H}_{\mathbf{4}}$ & $\mathbf{C}_{2} \mathbf{H}_{\mathbf{6}}$ & $\mathbf{C}_{2} \mathbf{H}_{\mathbf{4}}$ & $\mathbf{C}_{2} \mathbf{H}_{2}$ \\
\hline Accuracy & $\begin{array}{c} \pm 5 \% \text { or } \\
5 \mathrm{ppm}\end{array}$ & $\begin{array}{c} \pm 5 \% \text { or } \\
2 \mathrm{ppm}\end{array}$ & $\begin{array}{c} \pm 5 \% \text { or } \\
2 \mathrm{ppm}\end{array}$ & $\begin{array}{c} \pm 5 \% \text { or } \\
2 \mathrm{ppm}\end{array}$ & $\begin{array}{c} \pm 5 \% \text { or } \\
0.5 \mathrm{ppm}\end{array}$ \\
\hline $\begin{array}{c}\text { Detection } \\
\text { Range } \\
(\mathbf{p p m})\end{array}$ & $\begin{array}{c}5- \\
5,000\end{array}$ & $\begin{array}{c}2- \\
50,000\end{array}$ & $\begin{array}{c}2- \\
50,000\end{array}$ & $\begin{array}{c}2- \\
50,000\end{array}$ & $\begin{array}{c}0.5- \\
50,000\end{array}$ \\
\hline
\end{tabular}

\section{RESULTS AND DATA ANALYSIS}

\section{A. Data Processing}

In this section, the mass transfer coefficient of dissolved methane $\left(\mathrm{CH}_{4}\right)$ is calculated as an example. The mass transfer coefficients at various temperatures are calculated based on experimental results. The relationship between mass transfer coefficients and temperature is further determined.

The relationship between dissolved gas concentration and elapsed time will follow (2) in which the mass transfer coefficient $K$ can be calculated in terms of a linear curve fitting on the natural logarithmic gas concentration as shown in Fig.3. Based on known oil surface area and volume, mass transfer coefficient of the gas can be derived according to the slope. The R-square is very close to 1 which shows that the test follows the mass transfer model.

The relationship between mass transfer coefficient and temperature is derived based on Arrhenius equation in (4). The pre-exponential factor $A$ and activation energy $E_{A}$ can be calculated according to the slope and intercept in the Arrhenius plot. The Arrhenius plot of the methane mass transfer coefficient is shown in Fig.4.

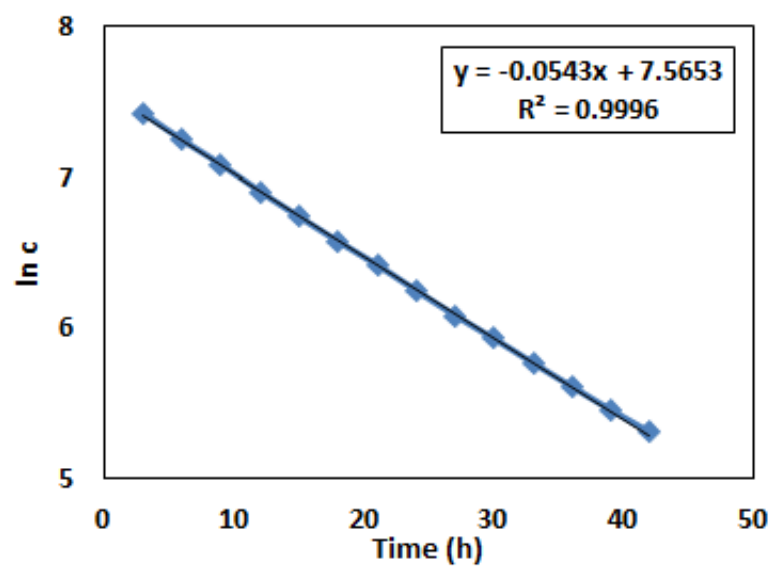

Fig.3. Curve fitting of logarithmic methane concentration versus time.

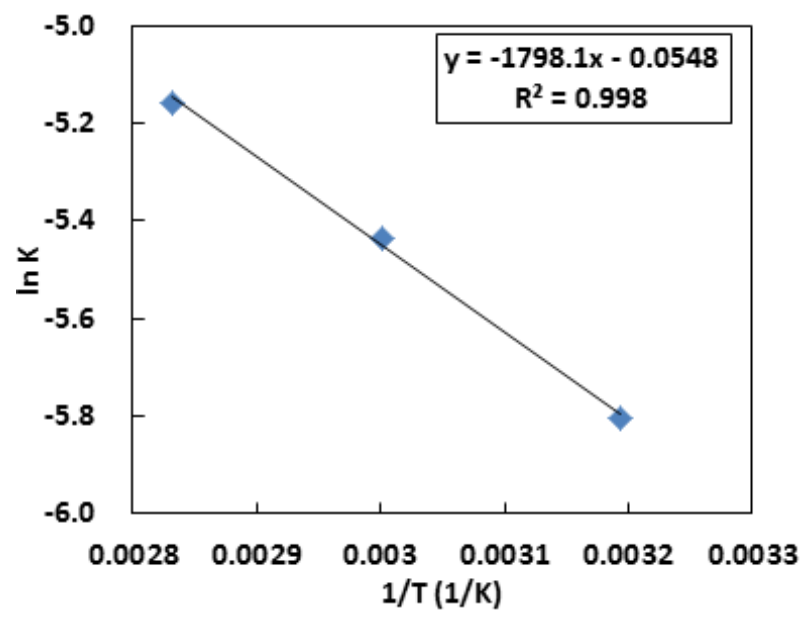

Fig.4. Arrhenius plot of methane mass transfer coefficient.

\section{B. Experimental Results}

The mass transfer coefficients of fault gases from Gemini X mineral oil to atmosphere at different temperatures are listed in Table 3.

In general, the mass transfer coefficients of all the investigated gases increase with environmental temperature rising. The dissolved gases will leak faster at higher temperature. In addition, the mass transfer coefficient of hydrogen is almost two times of the hydrocarbon gases at the same temperature. And the mass transfer coefficients of all the hydrocarbon gases are similar. Therefore, the leakage of dissolved hydrogen from mineral oil will be much faster than other hydrocarbon fault gases.

Table 3. Mass transfer coefficients of dissolved gases from mineral oil to air.

\begin{tabular}{|c|c|c|c|c|c|}
\hline Temperature & $\begin{array}{c}\mathbf{H}_{\mathbf{2}} \\
\left(\times \mathbf{1 0}^{\wedge} \mathbf{3}\right)\end{array}$ & $\begin{array}{c}\mathbf{C H}_{\mathbf{4}} \\
\left(\times \mathbf{1 0}^{\wedge} \mathbf{3}\right)\end{array}$ & $\begin{array}{c}\mathbf{C}_{2} \mathbf{H}_{\mathbf{6}} \\
\left(\times \mathbf{1 0}^{\wedge} \mathbf{3}\right)\end{array}$ & $\begin{array}{c}\mathbf{C}_{2} \mathbf{H}_{\mathbf{4}} \\
\left(\times \mathbf{1 0}^{\wedge} \mathbf{3}\right)\end{array}$ & $\begin{array}{c}\mathbf{C}_{2} \mathbf{H}_{\mathbf{2}} \\
\left(\times \mathbf{1 0}^{\wedge} \mathbf{3}\right)\end{array}$ \\
\hline $\mathbf{8 0}^{\mathbf{}} \mathbf{C}$ & 12.2 & 5.8 & 5.9 & 6.5 & 6.2 \\
\hline $\mathbf{6 0}^{\mathbf{o}} \mathbf{C}$ & 10.9 & 4.4 & 3.8 & 4.4 & 4.6 \\
\hline $\mathbf{4 0}^{\mathbf{}} \mathbf{C}$ & 8.0 & 3.0 & 2.7 & 3.1 & 3.2 \\
\hline
\end{tabular}


Subsequently, from the Arrhenius plots of the mass transfer coefficients, the activation energy and pre-exponential factor of mass transfer of fault gases are listed in Table 4. It can be found that the activation energy of hydrogen is much lower than the hydrocarbon gases, probably because the molecular size of hydrogen is much smaller than the hydrocarbons.

Table 4. Activation energy of dissolved gases mass transfer process.

\begin{tabular}{|c|c|c|c|c|c|}
\hline & $\mathbf{H}_{\mathbf{2}}$ & $\mathbf{C H}_{\mathbf{4}}$ & $\mathbf{C}_{2} \mathbf{H}_{\mathbf{6}}$ & $\mathbf{C}_{\mathbf{2}} \mathbf{H}_{\mathbf{4}}$ & $\mathbf{C}_{2} \mathbf{H}_{\mathbf{2}}$ \\
\hline $\begin{array}{c}\text { Activation } \\
\text { Energy } \boldsymbol{E}_{\boldsymbol{A}} \\
(\mathbf{m J} / \boldsymbol{\mu m o l})\end{array}$ & 9.6 & 14.9 & 17.5 & 16.8 & 15.5 \\
\hline $\begin{array}{c}\text { Pre-exponential } \\
\text { Factor } \boldsymbol{A}(\mathbf{m} / \mathbf{s})\end{array}$ & 0.33 & 0.95 & 2.25 & 1.92 & 1.22 \\
\hline
\end{tabular}

\section{EXAMPLE OF APPLICATION}

As discussed hereinabove, the dissolved gas leakage rate in sampling bottle can be evaluated according to the known mass transfer coefficients. Assuming one liter of mineral oil is sampled by a bottle for a DGA test, and the oil temperature is $55^{\circ} \mathrm{C}$. For some reason the oil is left open in air for 10 minutes. The oil surface area is known. The remaining gas contents in the oil are estimated and listed in Table 5. The temperature changing and difference is neglected.

Table 5. Remaining dissolved gas contents after 10 minutes of leakage.

\begin{tabular}{|c|c|c|c|c|c|}
\hline $\begin{array}{c}\text { Oil } \\
\text { Temperature } \\
\left({ }^{\circ} \mathbf{C}\right)\end{array}$ & $\mathbf{H}_{\mathbf{2}}$ & $\mathbf{C H}_{\mathbf{4}}$ & $\mathbf{C}_{2} \mathbf{H}_{\mathbf{6}}$ & $\mathbf{C}_{2} \mathbf{H}_{\mathbf{4}}$ & $\mathbf{C}_{2} \mathbf{H}_{2}$ \\
\hline $\mathbf{5 5}{ }^{\circ} \mathbf{C}$ & $98.97 \%$ & $99.58 \%$ & $99.62 \%$ & $99.56 \%$ & $99.56 \%$ \\
\hline
\end{tabular}

Based on this calculation, it can be found that all these fault gases mostly remain in oil after getting in contact with air for 10 minutes. In the oil sample, about $1 \%$ of hydrogen $\left(\mathrm{H}_{2}\right)$ leaks out. The leakage ratios of other gases are around $0.5 \%$. All the percentages are relative to the initial gas content. The dissolved gas leakage amount in 10 minutes or a shorter duration during sampling process is negligible.

The dissolved gas concentration detection interval is limited by the measurement technique. In the application, there is an assumption that the gas leakage trend continuously fit the theoretical model, since 10 minutes gas leakage duration is applied in practical application. This shall be further improved. In addition, although the gas leakage is negligible, open bottle might cause other issues, for instance, moisture migration, contamination and so on. Therefore, proper sealed method such as syringes should be prior to open bottles in oil sampling process.

\section{CONCLUSION}

The dissolved gas leakage from mineral oil can be simulated by a mass transfer model based on two-film theory. The mass transfer coefficients of hydrogen and fault hydrocarbon gases at various temperatures are calculated in terms of experiments. At higher temperature, dissolved gases tend to leak faster. It is found that the hydrogen leaks faster than the other hydrocarbon gases. The leakage rates of these hydrocarbon gases are similar.

The mass transfer coefficient at certain temperature can be effectively predicted by the Arrhenius equation. Based on the model, dissolved fault gas leakage amount is negligible, while proper sealing condition is still important in oil sampling.

\section{ACKNOWLEDGMENT}

The authors would like to express their gratitude to M\&I Materials, National Grid, Scottish Power, Shell Global Solutions, TJ $\mid \mathrm{H} 2 \mathrm{~b}$ Analytical Services, UK Power Networks and WEIDMANN Electrical Technology for their financial and technical contributions to the transformer research consortium at The University of Manchester.

\section{REFERENCES}

[1] M. Duval, "Dissolved gas analysis: It can save your transformer," IEEE Electrical Insulation Magazine, vol. 5, no. 6, pp. 22-27, 1989.

[2] Z.D. Wang, X. Wang, X. Yi et al., "Gas generation in natural ester and mineral oil under partial discharge and sparking faults," Electrical Insulation Magazine, IEEE, vol. 29, no. 5, pp. 62-70, 2013.

[3] Z.D. Wang, X. Yi, J. Huang et al., "Fault gas generation in natural-ester fluid under localized thermal faults," Electrical Insulation Magazine, IEEE, vol. 28, no. 6, pp. 45-56, 2012.

[4] "Method of sampling insulating liquids," IEC Std 60475, 2011.

[5] W. G. Whitman, "The two film theory of gas absorption," Chemical and Metallurgical Engineering, vol. 5, no. 29, pp. 429-433, 1923.

[6] M.Y.Chisti, "Airlift bioreactors," Elsevier, ed., 1989.

[7] T. R. Marrero, and E. A. Mason, "Gaseous diffusion coefficients," Journal of Physical and Chemical Reference Data, vol. 1, no. 1, pp. 3-118, 1972.

[8] D. F. Mielewski, N. R. Anturkar, and D. R. Bauer, "Estimation of Diffusion and Solubility Coefficients for Water and $\mathrm{CO}_{2}$ in Reaction Injection Molded Parts," Polymer Composites, vol. 17, no. 5, pp. 649-655, 1996. 